\title{
ANALISIS ANTRIAN PELAYANAN OBAT NON RACIKAN DI INSTALASI FARMASI RAWAT JALAN
}

\author{
WAITING LINE ANALYSIS PATENT DRUGS SERVICES IN PHARMACY OUTPATIENT SERVICES
}

Aris Sujoko, Djazuly Chalidyanto

Fakultas Kesehatan Masyarakat, Universitas Airlangga, Surabaya

Email: aris.jabung@gmail.com

\begin{abstract}
During 2013 until 2014, pharmacy outpatient services had not reached indicator of the standard minimum service. The average time of respons time was over the standard minimum service. It caused complain from patient, in 2014 the highest complain was 83\% about time services. The objective of this research was to find better model queueing system to decrease the waiting time. This study is a quantitative descriptive study with cross sectional design and observational method. The sample calculated by proportional random sampling formula, with 74 prescription and collected by accidental random sampling in peak time. Primary data was obtained by observation and secondary data was collected from documentations in pharmacy outpatients service. The highest service time occured in drugs preparation process with 3.71 minutes and the highest waiting time occured in last checking drugs process. The highest utilization rate occurred in drugs preparation process with $256 \%$ and after simulation became $73 \%$ with increased service rate in $81 \%$. The lowest utilization rate occurred in giving drugs process was $19 \%$. The conclusion from this study was the drugs preparation process had high workload and caused queueing. A suggestion from this research was to add workload for giving drugs process to help drugs preparation process.
\end{abstract}

Keywords: outpatient pharmacy, queueing system, simulation

\section{PENDAHULUAN}

Berdasarkan Surat Keputusan Menteri Kesehatan Republik Indonesia Nomor 1197 Tahun 2004 Tentang Standar Pelayanan Farmasi Rumah Sakit, menyebutkan bahwa pelayanan farmasi rumah sakit adalah bagian yang tidak terpisahkan dari sistem pelayanan kesehatan yang berorientasi kepada pelayanan pasien dan penyediaan obat yang bermutu. Pada Surat Keputusan Menteri Kesehatan tersebut juga sudah mengatur tentang pelayanan klinik yang terjangkau bagi semua lapisan masyarakat. Dalam Permenkes No.58 Tahun 2014 tentang Standar Pelayanan Kefarmasian di Rumah Sakit, bahwa standar pelayanan kefarmasian di rumah sakit meliputi standar pengelohan sediaan farmasi, alat kesehatan, bahan medis habis pakai serta pelayanan farmasi klinik.

Instalasi Farmasi Rumah Sakit Islam Jemursari mempunyai dua unit pelayanan resep dan alat kesehatan yaitu unit rawat jalan yang melayani resep dari poliklinik rawat jalan dan unit rawat inap yang melayani resep dari rawat inap. Pelayanan tersebut terbagi dalam lima depo yaitu depo 1, 4 dan 5 untuk pelayanan resep rawat jalan serta depo 2 dan 3 untuk pelayanan resep rawat inap. Instalasi Farmasi Rumah Sakit Islam Jemursari juga memiliki Unit Farmasi Klinis dan Unit Perlengkapan dan Sterilisasi.

Kunjungan pasien rawat jalan ke pelayanan Instalasi Farmasi Rawat Jalan Depo 1 meningkat sebesar $68 \%$ pada tahun 2014 . Hal ini dikarenakan pada tahun 2014 pihak rumah sakit memulai melakukan kerja sama dengan pihak Badan Penyelenggara Jaminan Sosial (BPJS). Dampaknya adalah jumlah resep yang harus dilayani oleh petugas menjadi semakin tinggi. Tingginya tingkat kedatangan resep ini menyebabkan proses 
pelayanan menjadi lebih lamban sehingga berpengaruh terhadap waktu tunggu yang lama.

Tingginya resep ini menyebabkan response time tidak sesuai Standar Pelayanan Minimum (SPM) Rumah Sakit Islam Jemursari yaitu untuk obat non racikan mencapai rerata 28,53 menit dengan standar 15 menit dan untuk obat racikan mencapai rerata 44 menit dengan standar 30 menit. Rasio resep yang masuk antara resep racikan dan non racikan adalah $1: 10$. Dapat disimpulkan bahwa resep non racikan memiliki jumlah kedatangan yang lebih tinggi daripada resep racikan. Selain itu, berdasarkan hasil survei oleh Instalasi Farmasi Rawat Jalan Depo 1 membuktikan bahwa keluhan pasien tertinggi adalah kecepatan pelayanan resep yang lambat 83\% pada tahun 2014.

Masalah yang diangkat pada penelitian ini adalah tidak tercapainya SPM Kefarmasian tentang response time dengan rerata waktu 44 menit pada obat non racikan dan keluhan sebesar $83 \%$ pada kecepatan pelayanan petugas dalam melayani resep. Penelitian ini dibatasi pada resep non racikan karena memiliki jumlah kedatangan resep yang tinggi serta hanya pada Depo 1 karena memiliki kenaikan kunjungan sebesar $68 \%$. Tujuan penelitian ini adalah melakukan identifikasi sistem antrian dan diharapkan menjadi bahan acuan untuk mengetahui waktu tunggu pada serta pengaturan petugas yang ideal saat kondisi mencapai waktu sibuk.

\section{PUSTAKA}

Teori antrian pertama kali ditemukan oleh A.K Erlang tahun 1913 yang mempelajari permintaan telepon dan keterlambatan pelayanan. Saat ini analisis antrian banyak digunakan dalam berbagai bidang bisnis (bank, supermarket), industri (pelayanan mesin otomatis) dan transportasi (Erlang, 2011). Menurut Russel \& Taylor (2005) antrian adalah garis tunggal yang menunggu atau terbentuk di depan fasilitas pelayanan. Hal ini terjadi karena frekuensi waktu orang (pasien) atau benda yang tiba pada suatu fasilitas pelayanan lebih cepat daripada orang (pasien) atau benda yang sedang mendapat pelayanan. Tujuan dari model antrian adalah untuk meminimumkan total dua biaya, yaitu biaya langsung penyediaan fasilitas pelayanan dan tidak langsung yang timbul karena para individu harus menunggu untuk dilayani.

Dalam teori antrian terdapat enam karakteristik dasar yaitu sumber masukan, pola kedatangan, pola pelayanan, disiplin antrian, kapasitas sistem, dan tingkat pelayanan (Siagian $\mathrm{P}$, 1987). Pola kedatangan (arrival pattern) adalah bagaimana cara individu dari suatu populasi memasuki suatu sistem antrian. Pola kedatangan (arrival pattern) tersebut dapat konstan atau secara random. Kedatangan dianggap sebagai kedatangan yang acak bila kedatangan tersebut tidak terikat satu sama lain dan kejadian kedatangan tidak dapat diramalkan secara tepat. Pola kedatangan juga dapat teratur atau konstan, kedatangan yang teratur sering kita jumpai dalam proses pembuatan produk yang sudah distandardisasi. Pada proses semacam ini, kedatangan produk untuk diproses pada bagian selanjutnya biasanya sudah ditentukan waktunya, misalnya setiap 30 detik. Kedatangan individu dalam 
suatu populasi ke dalam sistem antrian bisa secara individu (single arrivals) maupun kelompok atau bulk arrivals (Subagyo, 2000).

Pola pelayanan adalah waktu yang dibutuhkan untuk memberikan pelayanan yang dapat dikategorikan sebagai waktu konstan dan acak. Apabila waktu pelayanan konstan, maka waktu yang diperlukan untuk melayani setiap pelanggan adalah sama, yang sering terjadi banyak kasus adalah waktu pelayanan berdistribusi acak. Waktu pelayanan acak apabila waktu yang dibutuhkan untuk melayani berbeda-beda untuk setiap pelanggan. Tata letak fisik dari sistem antrian digambarkan dengan jumlah saluran atau disebut juga dengan jumlah pelayan. Model fasilitas antrian ada empat macam yaitu single channel single phase, single channel multi phase, multi channel single phase dan multi channel multi phase (Manullang, 2002).

Single channel single phase adalah sistem antrian jalur tunggal yang menggunakan satu jalur untuk memasuki sistem pelayanan dan satu stasiun pelayanan. Dalam arti lain dalam sistem antrian tersebut hanya terdapat satu pemberi layanan dan satu jenis layanan yang diberikan. Single channel multi phase adalah sistem antrian jalur tunggal tahapan berganda yaitu fasilitas pelayanan yang menggunakan satu jalur yang memasuki sistem pelayanan dan ada lebih dari satu stasiun pelayanan. Dalam arti lain bahwa dalam sistem antrian tersebut terdapat lebih dari satu jenis layanan yang diberikan, tetapi dalam setiap jenis layanan hanya terdapat satu pemberi layanan. Multi channel single phase adalah sistem antrian jalur berganda satu tahap yang menggunakan dua atau lebih jalur untuk memasuki sistem pelayanan namun stasiun pelayanan hanya satu. Multi channel multi phase adalah fasilitas pelayanan yang menggunakan dua atau lebih jalur untuk memasuki sistem pelayanan dengan lebih dari satu stasiun pelayanan yang dilaluinya (Manullang, 2002).

Disiplin pelayanan menunjukkan pedoman keputusan yang digunakan untuk menyeleksi individu yang memasuki antrian untuk diprioritaskan mendapatkan layanan pertama. Terdapat beberapa bentuk disiplin pelayanan yaitu First Come First Served (FCFS), Last Come First Served (LCFS), Service In Random Services (SIRO), General Discipline (GD), Priority Services (PS) dan Emergency First (EF). First Come First Served (FCFS) yaitu disiplin pelayanan dengan prioritas pelanggan yang lebih dahulu datang akan dilayani lebih dahulu. Last Come First Served (LCFS) yaitu ketika individu yang terakhir masuk ke dalam sistem antrian dan akan lebih dahulu keluar meninggalkan sistem antrian. Service In Random Order (SIRO) yaitu apabila panggilan terhadap anggota antrian didasarkan pada probabilitas secara random. General Dicipline (GD) yaitu antrian diberikan secara acak kepada individu yang membutuhkannya. Priority Service (PS) yaitu pelayanan diberikan lebih dahulu kepada mereka yang mempunyai prioritas lebih tinggi walaupun pelanggan dengan lebih rendah datang lebih dahulu atau sedang dilayani. Emergency First (EF) yakni pelanggan yang memiliki kondisi lebih kritis akan ditangani / dilayani terlebih 
dahulu. Bentuk ini sering digunakan dalam rumah sakit atau fasilitas kesehatan.

D.G Kendall merumuskan notasi untuk menggambarkan model antrian berdasarkan pola kedatangan, distribusi waktu pelayanan, dan jumlah channel. Notasi ini berupa :

Arrival distribution / service time distribution / number of service channels open

Dalam menuliskan notasi kendall, probabilitas distribusi dapat dituliskan dengan beberapa huruf spesifik yaitu :

$\mathrm{M}$ : untuk menggambarkan distribusi poisson

D : untuk menunjukkan distribusi yang konstan (deterministic)

$\mathrm{G}$ : distribusi umum yang diketahui rata-rata dan variansnya.

\section{METODE}

Penelitian ini merupakan penelitian kuantitatif dengan metode penelitian observasional deskriptif. Rancang bangun penelitian yang digunakan adalah cross sectional. Teknik pengambilan data primer mengunakan metode observasi untuk menghitung waktu pelayanan dan waktu tunggu pada setiap tahapan pelayanan. Pengambilan data sekunder dengan cara pengolahan data response time selama waktu penelitian.

Populasi dalam penelitian ini adalah seluruh resep non racikan yang masuk ke Instalasi Farmasi Rawat Jalan Depo 1 yang berjumlah 1733 lembar resep non racikan. Sampel dipilih menggunakan metode proportional random sampling dan besar sampel pada penelitian ini adalah 74 lembar resep. Penelitian ini dilaksanakan pada bulan Agustus 2015 di Instalasi Farmasi Rawat Jalan Depo

1. Penelitian ini dilakukan pada waktu sibuk yaitu waktu yang memiliki jumlah kedatangan resep tertinggi yaitu pada pukul 09.00 s.d 11.00 (shift 1) dan pada pukul 19.00 s.d 21.00 (shift 2).

Data primer yang dikumpulkan melalui perhitungan waktu pelayanan dan waktu tunggu ditujukan untuk mengetahui arrival rate dan service rate. Data yang diperoleh kemudian dilakukan analisis menggunakan software antrian untuk mengetahui waktu rata-rata dalam antrian $(W q)$ dan waktu rata-rata dalam sistem (Ws). Setelah itu dirumuskan dalam notasi Kendalls (M/M/c) agar bisa dilakukan simulasi. Hasil simulasi ini ditujukan untuk mengetahui model antrian yang terbaik pada pelayanan resep non racikan di Instalasi Farmasi Rawat Jalan Depo 1.

\section{HASIL \& PEMBAHASAN}

\section{Waktu Pelayanan dan Waktu Tunggu}

Proses pelayanan resep non racikan terbagi dalam dua kategori waktu, yaitu waktu pelayanan dan waktu tunggu. Waktu pelayanan adalah waktu yang dibutuhkan petugas untuk menyelesaikan satu resep pada setiap proses pelayanan. Sedangkan waktu tunggu adalah waktu tunda atau idle sebuah resep tidak dilakukan pelayanan.

Berdasarkan Tabel 1 dapat diketahui bahwa proses penyiapan obat memiliki waktu pelayanan (service time) tertinggi yaitu 3.71 menit. Artinya dua orang petugas pada bagian ini membutuhkan waktu 3.71 menit untuk 
Tabel 1 Waktu Pelayanan dan Waktu Tunggu Pada Proses Pelayanan Obat Non Racikan Instalasi Farmasi Rawat Jalan Depo 1

\begin{tabular}{lcc}
\hline \multicolumn{1}{c}{ Aktivitas } & Waktu Pelayanan (Menit) & Waktu Tunggu (Menit) \\
\hline Penerimaan & 0.33 & 2.83 \\
\hline Penghargaan & 1.16 & 3.44 \\
\hline Pengecekan Awal & 0.32 & 4.81 \\
\hline Penyiapan Obat & 3.71 & 5.02 \\
\hline Pengecekan Akhir & 1.17 & 5.95 \\
\hline Penyerahan Obat & 0.27 & 3.74 \\
\hline Total Waktu & 6.96 & 25.79 \\
\hline
\end{tabular}

menyelesaikan satu lembar resep. Hal ini disebabkan karena pada proses penyiapan obat memiliki jumlah aktivitas terbanyak yang harus dikerjakan yang meliputi pengambilan obat, penulisan etiket obat dan pengemasan obat. Proses pengecekan akhir memiliki waktu tunggu (waiting time) tertinggi yaitu 5.95 menit. Artinya waktu idle atau tidak dilakukan pelayanan pada satu lembar resep untuk dilakukan tahap pengecekan akhir mencapai 5.95 menit. Hal ini dikarenakan pada proses pengecekan akhir petugas menunggu hingga terjadi penumpukan resep dengna jumlah tertenu untuk dilakukan pengecekan akhir.

Berdasarkan uraian di atas diperoleh total waktu pelayanan 6.96 menit dan total waktu tunggu 25.79 menit. Artinya waktu tunggu yang dihabiskan dalam proses pelayanan resep ini lebih lama 3.7 kali lebih besar dari waktu pelayanan yang sebenarnya. Faktor yang menyebabkan waktu tunggu lama adalah semakin banyak jumlah komponen obat dalam satu resep serta semakin banyak resep yang masuk pada waktu yang hampir bersamaan sehingga waktu yang dibutuhkan petugas farmasi dalam melayani resep obat non racikan menjadi lebih lama (Suripto, 2013).
Hal ini dapat dihubungkan dengan kepuasan pasien. Menurut Riniastuti (2013) ada beberapa faktor yang berpengaruh dalam kepuasan pasien rawat jalan yaitu perilaku petugas, mutu informasi dan fasilitas umum. Sedangkan waktu antrian tidak berhubungan dengan kepuasan pasien karena sebagian besar pasien menyatakan bahwa petugas segera memberikan pelayanan. Selain itu terdapat papan informasi yang jelas mengenai besaran waktu tunggu maksimum yang diberikan petugas.

Menurut Herjunianto (2014) pengelolaan persepsi waktu tunggu dapat menjadi kunci bagi rumah sakit untuk meningkatkan cakupan kepuasan layanan farmasi. Hal ini dimungkinkan karena adanya perbedaan antara harapan dan kenyataan layanan yang diterima. Pengelolaan persepsi waktu tunggu yang baik dapat menjadi kunci bagi rumah sakit untuk meningkatkan cakupan layanan farmasi seperti perilaku petugas yang ramah, informasi waktu tunggu yang jelas dan fasilitas umum sebagai pengalih ketika pasien menunggu.

\section{Model Antrian}

Berdasarkan hasil penelitian didapatkan distribusi kedatangan bersifat poisson atau acak, distribusi pelayanan bersifat eksponensial, desain 
pelayanan berbentuk single channel multi phase dengan disiplin antrian First Come First Served (FCFS) dan jumah populasi tidak terbatas (infinite).

\section{Waktu dalam Antrian (Wq) dan Waktu dalam Sistem (Ws)}

Untuk mengetahui besar waktu rata-rata dalam antrian $(W q)$ dan besar waktu rata-rata dalam sistem (Ws) maka terlebih dahulu harus dilakukan perhitungan Arrival rate $(\lambda)$ dan service rate $(\mu)$. Arrival rate $(\lambda)$ dihitung berdasarkan rerata jumlah kedatangan resep yang masuk dalam satu hari. Jumlah itu kemudian dibagi 14 karena dalam satu hari dilakukan penelitian selama 14 jam. Setelah itu dikonversi dalam jumlah resep per menit. Arrival rate ( $\lambda$ ) menggambarkan jumlah proses resep yang harus dilayani per satuan waktu. Semakin tinggi nilai arrival rate-nya maka semakin tinggi pula jumlah resep yang harus dilayani. Service rate $(\mu)$ dihitung berdasarkan nilai rata-rata waktu pelayanan sesuai hasil penelitian. Waktu rata-rata proses pelayanan menggunakan satuan menit.

Menurut Susanto (2014) waktu rata-rata dalam antrian (Wq) mengambarkan total waktu tunggu dalam proses pelayanan resep non racikan. Waktu rata-rata dalam antrian adalah waktu proses idle, atau tidak dilakukan pelayanan. Jadi, $W q$ adalah waktu yang dihabiskan satu lembar resep untuk mendapatkan proses pelayanan. Sedangkan waktu rata-rata dalam sistem (Ws) menunjukkan total waktu tunggu dan waktu pelayanan dalam alur / proses atau tahapan mulai dari masuk ke dalam alur tersebut hingga proses keluar dari alur tersebut. Berdasarkan analisis antrian dengan software antrian diperoleh waktu dalam antrian $(W q)$ dan waktu dalam system (Ws) dalam proses pelayanan resep non racikan pada instalasi rawat jalan depo 1 ditampilkan pada Tabel 2.

Pada Tabel 2 dapat dilihat bahwa tingkat kedatangan (arrival rate) sebesar 0.69 resep per menit artinya dalam setiap menit ada kurang lebih 0.69 yang harus diselesaikan atau 41 resep dalam satu jam. Tingkat pelayanan (service rate) terendah terjadi pada proses penyiapan obat sebesar 0.26 resep per menit. Artinya dalam satu menit petugas di bagian penyiapan obat hanya mampu melayani kurang dari satu resep saja atau hanya mampu melayani 15 resep dalam satu jam dengan jumlah resep yang masuk sebanyak 41 resep dalam satu jam. Sedangkan nilai waktu rata-rata dalam antrian $(W q)$ dan nilai waktu rata-rata dalam sistem (Ws) tertinggi terjadi pada proses pengecekan akhir dengan Wq sebesar 5.07 menit dan Ws sebesar 6.25 menit. Artinya dalam sub pelayanan pengecekan akhir memiliki waktu tunggu sebesar 5.07 menit dan tidak dilakukan pelayanan sedangkan waktu tunggu ditambah waktu pelayanannya adalah sebesar 6.25 menit. 
Tabel 2 Waktu dalam Antrian (Wq) dan Waktu dalam Sistem (Ws) Pada Setiap Proses Pelayanan Obat Non Racikan di Instalasi Farmasi Rawat Jalan Depo 1

\begin{tabular}{lcccc}
\hline \multicolumn{1}{c}{ Aktivitas } & $\begin{array}{c}\text { Arrival Rate (Resep } \\
\text { Per Menit) }\end{array}$ & $\begin{array}{c}\text { Service Rate (Resep } \\
\text { Per Menit) }\end{array}$ & Wq (Menit) & Ws (Menit) \\
\hline Penerimaan & 0.69 & 2.98 & 0.1 & 0.44 \\
\hline Penghargaan & 0.69 & 0.86 & 4.72 & 5.88 \\
\hline Pengecekan Awal & 0.69 & 3.07 & 0.09 & 0.42 \\
\hline Penyiapan Obat & 0.69 & 0.26 & - & - \\
\hline Pengecekan Akhir & 0.69 & 0.85 & 5.07 & 6.25 \\
\hline Penyerahan Obat & 0.69 & 3.7 & 0.06 & 0.3 \\
\hline
\end{tabular}

Namun pada proses penyiapan obat nilai Wq dan Ws tidak dapat dihitung hal tersebut disebabkan

nilai arrival rate lebih besar dari nilai service rate. Menurut Siagian (1987) suatu garis tunggu timbul disebabkan oleh kebutuhan akan layanan melebihi kemampuan (kapasitas) pelayanan atau fasilitas layanan sehingga pasien yang tidak dapat segera mendapatkan layanan disebabkan kesibukan pelayanan. Ketika arrival rate lebih besar daripada service rate maka akan terbentuk garis tunggu yang tidak terbatas dan pelayanan akan menjadi lama. Hal ini terjadi pada proses penyiapan obat sehingga pada proses ini terjadi garis tunggu yang panjang dan tidak diketahui nilai waktu rata-rata dalam antrian dan nilai waktu rata-rata dalam sistem. Untuk mengetahuinya perlu dilakukan simulasi dengan melakukan peningkatan service rate.

\section{Simulasi Peningkatan Service Rate}

Analisis antrian digunakan untuk mengurangi waktu tunggu pelanggan, memperbaiki waktu pelayanan, dan mengefisienkan penggunaan sumber daya manusia. Selain itu juga dapat berfungsi untuk menentukan jumlah operator ketika jam sepi agar pengeluaran biaya produksi menjadi efesien.

Agar dapat menghitung nilai Wq dan Ws pada proses penyiapan obat maka perlu diberikan simulasi dengan meningkatkan service rate sebesar $81 \%$. Angka ini diperoleh dari nilai perbandingan tertinggi antara $W q$ dengan $W s$, nilai perbandingan tertinggi menunjukkan pelayanan masih dapat dilayani tanpa menimbulkan antrian. Simulasi ini dilakukan untuk melihat keuntungan yang dapat terjadi dengan mempercepat proses pelayanan.

Menurut Susanto (2014) agar tidak terjadi kelebihan beban kerja, maka salah satu hal yang dapat dilakukan adalah melakukan simulasi peningkatan service rate. Dalam contoh sehari-hari, peningkatan service rate ini dapat terjadi apabila dalam kondisi normal jumlah resep yang dapat dilayani 100 resep per jam, oleh karena sebab tertentu jumlah pelayanan resep yang dapat dilayani menjadi 300 resep per jam. Sehingga service rate saat ini 0.26 resep per menit ditingkatkan sebesar $81 \%$ menjadi 0.47 resep per menit. 
Tabel 3 Utilitas Petugas Sebelum dan Sesudah Simulasi pada Proses Pelayanan Resep Non Racikan di Instalasi Farmasi Rawat Jalan Depo 1

\begin{tabular}{lcccccc}
\hline \multicolumn{1}{c}{ Aktivitas } & \multicolumn{3}{c}{ Sebelum Simulasi } & \multicolumn{2}{c}{$\begin{array}{c}\text { Setelah Simulasi } \\
\text { (Peningkatan Service Rate 81 \%) }\end{array}$} \\
\cline { 2 - 7 } & $\begin{array}{c}\text { Wq } \\
\text { (Menit }\end{array}$ & $\begin{array}{c}\text { Ws } \\
\text { (Menit) }\end{array}$ & $\begin{array}{c}\text { Utilitas } \\
\text { Petugas (\%) }\end{array}$ & $\begin{array}{c}\text { Wq } \\
\text { (Menit }\end{array}$ & $\begin{array}{c}\text { Ws } \\
\text { (Menit) }\end{array}$ & $\begin{array}{c}\text { Utilitas } \\
\text { Petugas (\%) }\end{array}$ \\
\hline Penerimaan & 0.1 & 0.44 & 23 & 0.1 & 0.44 & 23 \\
\hline Penghargaan & 4.72 & 5.88 & 80 & 4.72 & 5.88 & 80 \\
\hline Pengecekan Awal & 0.09 & 0.42 & 22 & 0.09 & 0.42 & 22 \\
\hline Penyiapan Obat & - & - & $\mathbf{2 5 6}$ & $\mathbf{2 . 4 9}$ & $\mathbf{4 . 6 3}$ & $\mathbf{7 3}$ \\
\hline Pengecekan Akhir & 5.07 & 6.25 & 81 & 5.07 & 6.25 & 81 \\
\hline Penyerahan Obat & 0.06 & 0.3 & 19 & 0.06 & 0.3 & 19 \\
\hline
\end{tabular}

Pemilihan alternatif dengan mengubah service rate $(\mu)$ ini harus mengubah tingkat pelayanan di bagian penyiapan obat maka pekerjaan akan cenderung tidak teliti dan tergesa-gesa. Seperti yang terlihat dalam Tabel 3 di atas bahwa tingkat kegunaan petugas terbesar terjadi pada pada tahap penyiapan obat non racikan yaitu sebesar $256 \%$. Hal ini menunjukkan bahwa pada tahap penyiapan obat non racikan mengalami kelebihan beban kerja sebesar $156 \%$ (overload). Setelah dilakukan simulasi dengan peningkatan service rate sebesar $81 \%$ dan dilakukan analisis antrian $\mathrm{M} / \mathrm{M} / 2$ maka perhitungan utilitas petugas akan mengalami perubahan bahwa tingkat utilitas petugas di bagian penyiapan obat berubah dari $256 \%$ menjadi $73 \%$. Hal ini menunjukkan bahwa dengan memberikan simulasi dengan peningkatan service rate pada tahap penyiapan obat non racikan maka beban kerja tidak akan mengalami overload.

\section{SIMPULAN}

Berdasarkan hasil penelitian dapat disimpulkan bahwa model antrian yang terjadi pada proses pelayanan resep non racikan di Instalasi Farmasi Rawat Jalan RS Islam Jemursari Depo 1 adalah distribusi kedatangan bersifat poisson atau acak. Distribusi pelayanan bersifat eksponensial atau memiliki waktu yang berbeda antar resep. Desain pelayanan berbentuk single channel multi phase dengan disiplin antrian First Come First Served (FCFS) dan besar populasi tidak terbatas (infinite).

Proses yang memiliki tingkat utilitas petugas tertinggi adalah proses penyiapan obat sebesar 256\%. Hal tersebut menjadi penyebab terjadinya penumpukan resep pada tahap penyiapan obat karena ketidakmampuan petugas dalam melayanai resep yang masuk. Tingkat utilitas pada proses penyiapan obat tersebut melebihi beban kerja dan diluar kemampuan petugas penyiapan obat. Agar beban kerja menjadi optimal, maka perlu dilakukan rekayasa desain pekerjaan melalui simulasi pada saat pelayanan waktu sibuk

Setelah dilakukan simulasi dengan peningkatan service rate sebesar $81 \%$, tingkat utilitas menjadi 73\% (tidak melebihi beban kerja). Hasil simulasi menunjukkan bahwa jumlah petugas yang ideal pada proses penyiapan obat adalah 3 petugas. Pada proses penyiapan obat, petugasnya 
menjadi tiga orang yaitu dengan dua petugas penyiapan obat dan satu petugas dari proses penyerahan obat yang diberi tugas tambahan untuk membantu proses penyiapan obat karena memiliki tingkat utilitas terendah (19\%).

Saran yang diberikan adalah saat pelayanan mencapai kondisi maksimum untuk mengatasi masalah antrian Kepala Instalasi Farmasi dapat memberikan tugas tambahan kepada petugas penyerahan obat ke bagian penyiapan obat. Selain itu mengelola persepsi waktu tunggu dengan menampilkan waktu tunggu maksimum melalui media informasi televisi yang ada di Depo 1 dan petugas dibagian pengecekan akhir diharapkan melakukan pengecekan akhir ketika ada resep yang masuk pada saat itu juga tanpa menunggu resep menumpuk. Untuk peneliti yang lain perlu adanya penelitian mengenai perhitungan dan analisis antrian dengan biaya langsung maupun biaya tidak langsung.

\section{DAFTAR PUSTAKA}

Ahse, N.S. (2014). Analisis Sistem Antrian untuk Menentukan Tingkat Pelayanan yang Optimal pada Kasir (Server) Rumah Makan Kober Mie Setan Malang dengan Metode Simulasi. Jurnal Skripsi. Malang; Universitas Brawijaya.

Erlang, A.K. (2011). "Sejarah Teori Antrian" dalam modul manajemen operasional. Jakarta.
Herjunianto. (2014). Faktor yang Mempengaruhi Cakupan Layanan Farmasi di Instalasi Farmasi Rawat Jalan Rumah Sakit. Jurnal Fakultas Kedokteran Fakultas Kedokteran Volume 28.

Manullang, I. (2002). Pengembangan Model Antrian Resep di Depo Farmasi Unit Rawat Jalan "Sore Hari" RS PGI Cikini Jakarta Pusat. Tesis. Fakultas Kesehatan Masyarakat, Universitas Indonesia.

Peraturan Menteri Kesehatan No. 58 Tahun 2014 tentang Standar Pelayanan Kefarmasian di Rumah Sakit.

Russel, R.S. and Taylor B. W. (2005). Operation Management-third edition.Prentice-Hall, New Jersey.

Siagian, P., (1987), Penelitian Operasional: Teori dan Praktek, Universitas Indonesia Press, Jakarta.

Subagyo, Pangestu. Asri, Marwan. Handoko, T. Hani. (1983). Dasar - dasar Operations Research. BPFE. Yogyakarta.

Subagyo, P. (2000). Dasar-Dasar Operations Research. BPFE. Yogyakarta.

Sujoko, A. (2015). Pengembangan Model Antrian Pelayanan Obat Pasien Non Racikan di Depo 1 Unit Rawat Jalan Instalasi Farmasi RS Islam Jemursari. Skripsi. Universitas Airlangga Surabaya.

Surat Keputusan Menteri Kesehatan Republik Indonesia Nomor 1197/Menkes/SK/X/2004 Tentang Standar Pelayanan Farmasi Rumah Sakit.

Susanto, Nikolas Dwi. (2014). Analisis Waktu Tunggu Pemulangan Pasien Rawat Inap di RS Premier Surabaya dengan Teori Antrian dan Metode Six Sigma. Thesis. Fakultas Kesehatan Masyarakat, Universitas Airlangga. Surabaya.

Undang - Undang No. 44 Tahun 2009 tentang Rumah Sakit.

Riniyastuti, K. Rimawati, E. Astuti, R. (2013). Faktor - Faktor yang Berhubungan dengan Kepuasan Pasien TPPRJ RSUD RA Kartini Jepara tahun 2013. Jurnal Skripsi. Jepara

Suripto, D.A. (2013). Gambaran Pengetahuan, Masa Kerja Petugas dan Waktu Tunggu Pasien Rawat Jalan di Instalasi Farmasi RSUD Surakarta Tahun 2013. Jurnal Skripsi. Surakarta.

Sareong, K.M. (2013). Faktor yang Berhubungan dengan Kepuasan Pasien Rawat Jalan di Puskesmas Rantepao kabupaten Toraja Utara Tahun 2013. Jurnal Skripsi. 